\title{
Strength Characteristics of Rammed Earth Using Hwangtoh Binder
}

\author{
Hwang, Hey-Zoo ${ }^{1}$ Yang, Jun-Hyuk ${ }^{2 *}$ \\ Department of Architecture, Mokpo national University, Muan-gun, Jeollanam-do, 534-729, Korea ${ }^{1}$ \\ Claymax Co.,Itd, Gangnam-gu, Seoul, 135-100, Korea ${ }^{2}$
}

\begin{abstract}
There has recently been a great deal of research into the appropriate building materials for eco-friendly construction. In the field of earth architecture, there have been walls made of pure earth or with rammed earth including a small amount of cement. The purpose of the study is to investigate the possibility increasing compressive strength through a more eco-friendly composition by using Hwangtoh binder rather than cement to increase the strength performance of rammed earth. It was found that the more the ratio of binder was increased, the more the strength was increased, but enhancement did not increase noticeably in the lower part that did not compact completely, and proper height to pour earth is $200 \mathrm{~mm}$. When stone dust was added, compressive strength was lower than when adding fine aggregate and coarse aggregate, but a finer surface texture was provided.
\end{abstract}

Keywords : rammed earth, hwangtoh binder, green materials

\section{Introduction}

\subsection{Research Objective}

First manufactured and used in 1825 in England, Portland cement was used in the construction of social infrastructures to meet the needs of the times, including roads, railways, ports and building structures, making a great contribution to global economic growth. Portland cement was introduced in Korea during Japanese colonial rule, and has been used in building the currently used social infrastructure. Despite its contributions, concrete is perceived negatively as an environmental pollutant, specifically in relation to the environmental and health aspects of the cement manufacturing

Received : May 31, 2012

Revision received : November 2, 2012

Accepted : November 27, 2012

* Corresponding author : Yang, Jun-Hyuk

[Tel: 82-2-518-4663, E-mail: yjhzzang @hotmail.com]

(c)2013 The Korea Institute of Building Construction, All rights reserved. process. As a result of this trend, as Koreans have taken a keen interest in the environment, a traditional wall building method, the rammed earth wall, has been given attention.

The rammed earth wall is a method used to harden the earth in a mold. To make the rammed earth wall, wet earth is used, the pores in the earth are reduced by the ramming pressure, and the density of the rammed earth is increased as a result. The rammed earth wall was used in traditional construction; but as the interest in its unique pattern picks up, demand for rammed earth has been on the rise.

Rammed earth building structures are known to have been developed in the ancient civilizations of Egypt, Minos and Rome[1,2]. Thanks to the efforts of UNESCO, earthen houses are being preserved all over the world. In particular, since the oil shock of the 1970s, earthen houses have been built once again using cutting-edge technologies, in numerous countries including Germany. Building structures with 
rammed earth walls offer improved air quality and temperature and a humidity-controlled fresh space. Even considering that under dry conditions, the density of earth stands at 1,800 2,200 kg/m compressive strength at $1.3 \mathrm{MPa}$, which are lower than those of concrete or red bricks and are known as a weakness[3], there is almost no environmental load when only the earth is used without any other materials added, and the buildings have little negative impact on the environment. Notwithstanding this, rammed earth walls are reported to have problems with durability, like separation from and destruction of the surface by wind or rainwater as well as strength. For this reason, rammed earth walls need frequent repairs, and thus to improve compressive strength of earth and reinforce the durability of the walls, a binder is added[4].

Thus, unlike the conventional rammed walls, which have a small amount of cement added for strength performance, the rammed earth in this study was only mixed with a Hwangtoh binder, and not with any cement. This study aims to understand the compressive strength of the rammed earth specimens and constructability when using dry earth with the Hwangtoh binder.

\subsection{Research method and scope}

This study is about one of the representative earth construction methods. In this study, a Hwangtoh binder made of Hwangtoh and lime[5] was added for comparison with traditional rammed earth. Traditional rammed earth not only has poor durability but is also hard to use in construction due to ramming and the cost of labor.

The goal of this study was to determine the compressive strength of the Hwangtoh-mixed earth according to W/B, unit binder weight, and mixing amount of admixture. The mixing ratio appropriate for the rammed earth was derived through a preliminary experiment. The earth used in this study is rammed, but not placed. When rammed, the ramming pressure was set to be lower than that used for wet earth in consideration of the Plastic condition of the earth. As indicated in 3.3 Preliminary experiments for rammed earth, the earth was rammed and compressed either by hand or by a machine. The earth that was rammed in this way could endure external stress, and as more ramming energy was applied with the passage of time, the pores were reduced and the strength was improved, accordingly. Based on the rammed earth method widely used in Korea, the earth was mixed with an appropriate amount of water to achieve the desired fluidity for this study. The W/B was calculated to be within the range of $0 \sim 10 \mathrm{~mm}$ slump, and the placement height was set as $150 \mathrm{~mm}$, 200mm, and $250 \mathrm{~mm}$ to perform a comparative analysis of compressive strength according to height. In addition, the aggregate used in his study was mixed with gravel and sand, as is in concrete, and with stone powder to determine its usability as aggregate in rammed earth.

\section{A review of previous studies}

\subsection{Characteristics of rammed earth method}

Earth that has viscosity shows different properties according to its water content. If there is too much water, earth particles float on water first. As water content decreases with the passage of time, it turns slurry, semi-solid and finally solid[6]. Unlike concrete, the rammed earth method using the wet state of earth does not require high strength, and it is believed to be effective when used in earth construction instead of concrete. It has been revealed that different geological features 
and weather conditions around the world affect the grain sizes of earth. There are some records of experiments using literite and clay as the earth block mixed with cement. In India, the strength of the earth brick was measured at $2.5 \mathrm{Mpa}$, and bricks were used instead of mortar. The strength of the earth block mixed with cement was measured at $2-4.5 \mathrm{MPa}$, and there was one case in which it was mixed more than $6 \%$ to make walls, and exceeded 0.9Mpa[7]. A steel rammer was used for ramming, and thin steel or plywood was used as a mold. In Sri Lanka, there was a case in which a single story building was built within a short period of time using a ramming method, in which a vertical steel sliding mold system was introduced. In particular, although 50\% of labor was used up to put molds together, take them apart after construction, clean and transport them, the mold system can be used several times. But the inconvenience and high labor cost has prevented several countries from introducing and applying the system, and they are seeking a better solution.

In Korea, there were some cases in which houses were built in Gunsan after the Korean War using a rammed earth method, as shown in Figure 1 (a), and a machine rammer has been used in many construction projects, as shown in Figure 1 (b). At Bath University (UK), there was a case in which the compressive strength of rammed earth with only earth was measured at about 1.0-3.0MPa. It reported that earth in which gravel and clay are distributed evenly is ideal, and laterite showed better performance than clay when mixed with cement[3]. The type of earth for rammed earth could pass unnoticed, but when earth has too much clay, the surface texture may be improved, but cracks can occur after construction. On the other hand, when earth has too little clay, the particles cannot be combined with each other and the surface becomes tough, which might have an impact on the durability of the structure. For these reasons, the type of earth used for rammed earth is an important factor. In addition, when too little water is mixed, the earth particles cannot be combined properly, and in terms of strength it is inefficient when the mold is removed. On the other hand, when too much water is mixed, viscosity becomes high, which affects the density of earth.

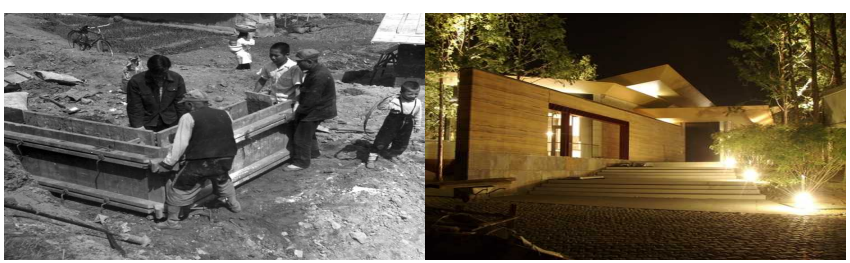

(a) Applied form wall of rammed earth, Gunsan, 1952 (b) Yangpeong Orion Training Institution
Figure 1. Form and case of rammed earth

\subsection{Analysis of studies on rammed earth}

There have been few studies on rammed earth in Korea. Rammed earth is generally used in small construction projects locally, and the studies have relied heavily on fundamental data of foreign countries. Pure earth is used for rammed earth. However, when earth fails to meet the standard proctor compaction test, up to 3-8\% lime or cement is added for ramming. Unlike in foreign countries, domestic earth does not have sufficient clay, and it is hard to expect high strength. For this reason, a binder is needed, to improve the binding force. Lime has long been used as a binder, but currently cement is in wide use, and as lime is relatively more expensive than cement its use has been reduced. In foreign countries including the US and Austria, comparative analyses of rammed earth with pure earth and rammed earth with a binder have been actively performed 
to check resistance to weathering and strength through durability tests as shown in Figure 2[8]. In addition, some countries make the use of a binder compulsory in order to improve the safety of earthen structures. The mixing ratio of a binder was used within the range of $3-8 \%$ by mass. The most common binders include cement, lime, asphalt, and emersion. In particular, studies on binders have been continuously conducted in the US, the UK, and Germany due to their policies related to environmental protection.

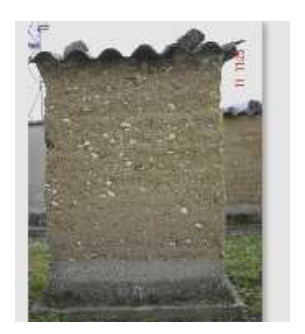

(a) Unstabilized rammed earth

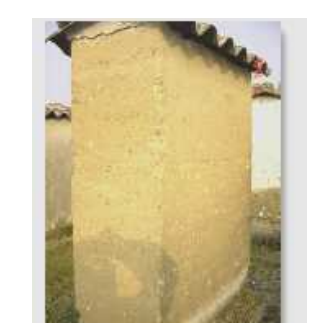

(b) Stabilized rammed earth
Figure 2. Rammed earth test cases

\section{Experiment}

\subsection{Experiment plan}

In this study, the mechanical properties of rammed earth were analyzed using Hwangtoh binder manufactured with earth by Company C. Based on the research data of the physical properties of Hwangtoh binder[5], strength was tested according to mixing condition and ramming height. As shown in Table 1, In terms of strength according to mixing condition, compressive strength was measured by varying the mix proportion of admixture $(0,1,2 \%)$ and unit binder (250, 300, 350, $300 \mathrm{~kg} / \mathrm{m}^{3}$ ). Sand and gravel, which are widely used in concrete, were used as aggregate. To diversify the use of gravel, Hwangtoh binder and stone powder were used. Admixture was mixed to be $2 \%$ and a different proportion according to mix proportion of unit binder (250,300,350, 400kg/m $)$. Strengths of machine-rammed specimens at placement height of $200 \mathrm{~mm}$ were compared.

Table 1. Experimental factors and levels

\begin{tabular}{|c|c|c|}
\hline Contents & Factors & Condition \\
\hline \multirow{6}{*}{$\begin{array}{l}\text { Binder+ } \\
\text { Sand+ } \\
\text { Gravel }\end{array}$} & $\mathrm{W} / \mathrm{B}(\%)$ & $25,30,35,40$ \\
\hline & $\begin{array}{l}\text { Unit binder contents } \\
\qquad\left(\mathrm{kg} / \mathrm{m}^{3}\right)\end{array}$ & $250,300,350,400$ \\
\hline & Admixture(\%) & $0,1,2$ \\
\hline & $\mathrm{S} / \mathrm{a}(\%)$ & 45 \\
\hline & Compact Height(mm) & $150,200,205$ \\
\hline & Compact Type & $\begin{array}{l}\text { Mechanical compaction, } \\
\text { Hand compaction }\end{array}$ \\
\hline \multirow{6}{*}{$\begin{array}{l}\text { Binder+ } \\
\text { Stone } \\
\text { powder }\end{array}$} & $\mathrm{W} / \mathrm{B}(\%)$ & $30 \sim 35$ \\
\hline & $\begin{array}{l}\text { Unit binder contents } \\
\qquad\left(\mathrm{kg} / \mathrm{m}^{3}\right)\end{array}$ & $250,300,350,400$ \\
\hline & Admixture(\%) & 2 \\
\hline & $\mathrm{S} / \mathrm{a}(\%)$ & 45 \\
\hline & Compact Height(mm) & 200 \\
\hline & Compact Type & Mechanical compaction \\
\hline
\end{tabular}

\subsection{Experiment material}

1) Hwangtoh binder

The Hwangtoh binder used in this study was made by mixing non-sintered natural Hwangtoh manufactured by Company $\mathrm{C}$ specialized in earth materials with lime and pozzolanic material. It was a powdery material specially developed for high strength. As shown in Table 2 and 3, the specific gravity was 2.47, which is lower than that of cement. The grain size and ignition loss were $3,483 \mathrm{~cm}^{2} / \mathrm{g}$ and $0.09 \%$, respectively.

Table 2. Chemical compositions of $\mathrm{HB}$ (Hwangtoh binder)

\begin{tabular}{cccccc}
\hline & \multicolumn{5}{c}{ Chemical composition (\% by weight) } \\
\cline { 2 - 6 } & $\mathrm{SiO}_{2}$ & $\mathrm{Al}_{2} \mathrm{O}_{3}$ & $\mathrm{Fe}_{2} \mathrm{O}_{3}$ & $\mathrm{CaO}$ & $\mathrm{MgO}$ \\
\hline $\begin{array}{c}\text { Hwangtoh } \\
\text { binder }\end{array}$ & 37.93 & 14.9 & 1.29 & 37.78 & 3.01 \\
\hline
\end{tabular}


Table 3. Physical properties of HB

\begin{tabular}{|c|c|c|}
\hline \multicolumn{2}{|c|}{ Type } & $\begin{array}{c}\text { Hwangtoh } \\
\text { binder }\end{array}$ \\
\hline \multicolumn{2}{|c|}{ Specific gravity $\left(\mathrm{g} / \mathrm{cm}^{3}\right)$} & 2.74 \\
\hline \multicolumn{2}{|c|}{ Blain fineness $\left(\mathrm{cm}^{\mathrm{m}} / \mathrm{g}\right)$} & 3,483 \\
\hline \multicolumn{2}{|c|}{ Ignition loss (\%) } & 0.09 \\
\hline \multicolumn{2}{|c|}{ Initial setting time (min) } & 209 \\
\hline \multicolumn{2}{|c|}{ Final setting time (min) } & 609 \\
\hline \multirow{3}{*}{$\begin{array}{l}\text { Compressive } \\
\text { Strength(MPa) }\end{array}$} & $7 \mathrm{D}$ & 11.1 \\
\hline & $14 \mathrm{D}$ & 21.9 \\
\hline & $28 \mathrm{D}$ & 36.6 \\
\hline
\end{tabular}

\section{2) Admixture}

The admixture used in this study is polycarboxylate superplasticizer, and the physical properties are indicated in Table 4.

Table 4. Physical properties of admixture

\begin{tabular}{cccccc}
\hline Ingredient & Density & $\mathrm{pH}$ & Color & Form & Usage \\
\hline $\begin{array}{c}\mathrm{PC} \\
\text { - Superplas } \\
\text { ticizer }\end{array}$ & 1.05 & 6.38 & $\begin{array}{c}\text { Dark } \\
\text { brown }\end{array}$ & Liquid & $\begin{array}{c}\text { Cement } \\
\text { * } 0.15 \%\end{array}$ \\
\hline
\end{tabular}

3) Sand and stone powder

As shown in Table 5, the sand used in this test was collected from a waterfall had grain size of less than $1.2 \mathrm{~mm}$. Its water content was $1.4 \%$. The grain size of sand is small because the rammed pattern was not expressed properly when using sand with grain size less than $5 \mathrm{~mm}$ in preliminary ramming tests. The size of sand was also determined through several preliminary tests, and fine aggregate was $45 \%$. Stone powder with a size of less than $13 \mathrm{~mm}$ was collected in Naju, and its water content was $1.65 \%$.

Table 5. Particle size distribution of Sand, stone powder

\begin{tabular}{|c|c|c|c|c|c|c|c|c|c|}
\hline $\begin{array}{l}\text { Size } \\
(\mathrm{mm})\end{array}$ & & 0.074 & 0.15 & 0.3 & 0.6 & 1.2 & 2.5 & 5 & $\begin{array}{c}5 \\
\text { more }\end{array}$ \\
\hline $\begin{array}{c}\text { Percentage } \\
(\%)\end{array}$ & Sand & 1.8 & 4.5 & 29.4 & 84.7 & 99.9 & 100 & - & - \\
\hline $\begin{array}{l}\text { Percentage } \\
(\%)\end{array}$ & $\begin{array}{l}\text { Stone } \\
\text { Powd } \\
\text { er }\end{array}$ & 1.6 & 4.2 & 10.7 & 22.7 & 37.7 & 58.9 & 84.3 & 100 \\
\hline
\end{tabular}

\section{4) Gravel}

As shown in Table 6 and Figure 3, the gravel used in this test was collected in Muan-gun, Jeollanam-do. Its water content was 1.8\%

Table 6. Particle size distribution of gravel

\begin{tabular}{ccccccccc}
\hline $\begin{array}{c}\text { Size } \\
(\mathrm{mm})\end{array}$ & pan & 2.5 & 5 & 10 & 15 & 20 & 25 & 30 \\
\hline $\begin{array}{c}\text { Percentage } \\
(\%)\end{array}$ & 0 & 9.0 & 16.1 & 42.2 & 79.4 & 93.0 & 100 & - \\
\hline
\end{tabular}

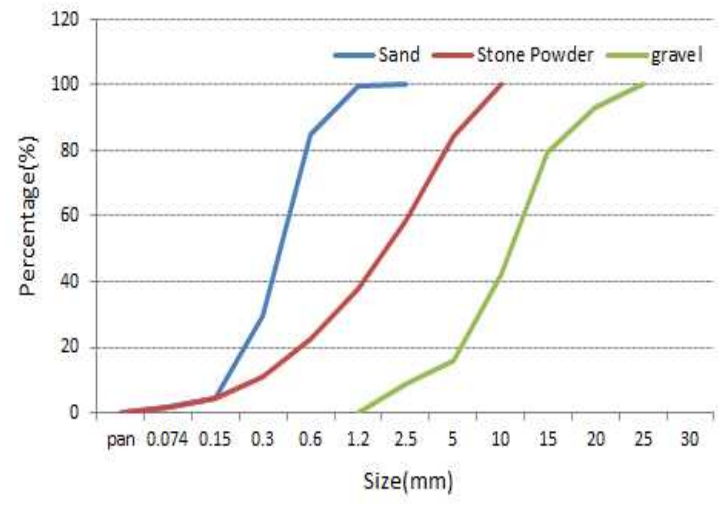

Figure 3. Particle size distribution curve of aggregates

\subsection{Ramming method}

To make the specimen molds needed for the test, an identical volume of specimen was placed at the bottom of $1 \mathrm{~cm}$, and rammed carefully to prevent destruction of the lower part when measuring compressive strength. A rammer (RM-18) and a 2HP compressor were used in ramming to maintain the ramming pressure at a certain level according to a certain air pressure. Each ramming time was set at 10 seconds. After finishing ramming, the top of the specimens was flattened using a plastering knife. $10 \times 20 \mathrm{~cm}$ cylindrical molds were used for the specimens placed from $15 \mathrm{~cm}$ and $20 \mathrm{~cm}$ of height. $15 \times 30 \mathrm{~cm}$ cylindrical molds were used for the specimens placed from $25 \mathrm{~cm}$ of height. To distinguish hand ramming and machine ramming before the test, preliminary tests were conducted as follows. When 
using the earth with $10 \%$ water content, the density was shown to be highest in machine-rammed specimens and in the Proctor method, as indicated in Table 7.

Table 7. Ramming affection of Earth

\begin{tabular}{cccc}
\hline \multirow{2}{*}{ Factor } & \multicolumn{2}{c}{ Height of earth } \\
\cline { 3 - 4 } Compact & Hand using wood & $60 \sim 65 \mathrm{~mm}$ & $150 \mathrm{~mm}$ \\
\hline \multirow{2}{*}{$\begin{array}{c}\text { method } \\
\end{array}$} & $\begin{array}{c}\text { Machine using } \\
\text { compressor }\end{array}$ & $60 \mathrm{~mm}$ & $80 \mathrm{~mm}$ \\
& Proctor test & $55 \mathrm{~mm}$ & $80 \mathrm{~mm}$ \\
\hline
\end{tabular}

\section{Experiment results}

\subsection{Compressive strength according to mix proportion of unit binder and ramming method}

In this test, superplasticizer was mixed to be $2 \%$ over Hwangtoh binder, and water was added to make the fluidity of the specimen appropriate for ramming. As shown in Table 8, the higher the mix proportion of the unit binder, the higher the compressive strength was found to be overall. In particular, when the mix proportion of unit binder was lower, no noticeable strength development was found in the comparison of the specimens at 7 days and at 28 days. It is believed that the upper part was rammed stably since the ramming pressure was directly put on the upper part of the specimens; however, since the density of the lower part was weak, and the ramming pattern was formed, more strength could not be developed. In addition, the higher the mix proportion of unit binder, the higher the compressive strength measured. As shown in Figure 4, the compressive strength was developed noticeably in the specimens with 350 and 400 of mix proportion of unit binder. When compared with the specimens with 350 and 400 mix proportion of unit binder, there was no noticeable difference in compressive strength at initial age, while the difference in compressive strength became greater with the passage of time. Through the test results, it is found that to develop high strength in the rammed earth with Hwangtoh binder, the mix proportion of unit binder is believed to have played an important role, and the appropriate mix proportion of superplasticizer is important, accordingly.

In terms of the ramming method, compressive strength of specimens rammed by a rammer with greater ramming pressure was measured to be higher than that of specimens rammed by hands. It is believed that higher strength was developed in the specimens rammed by the rammer because the pores in the earth might be reduced in the physical aspect, and the W/B ratio for pozzolanic reaction might be reduced in the chemical aspect.

Table 8. Compaction compressive strength of Hwangtoh binder

\begin{tabular}{|c|c|c|c|c|c|}
\hline \multicolumn{2}{|c|}{ Factor } & \multicolumn{4}{|c|}{ Compressive strength(MPa) } \\
\hline Aggregate & Name & 1 day & 3day & 7day & 28day \\
\hline \multirow{13}{*}{$\begin{array}{l}\text { Sand+ } \\
\text { Gravel }\end{array}$} & $250-0-40-150$ & 1.47 & 3.72 & 4.54 & 4.19 \\
\hline & $250-1-35-150$ & 1.60 & 4.41 & 6.35 & 6.13 \\
\hline & $250-2-35-200$ & 3.12 & 7.58 & 11.9 & 11.4 \\
\hline & $250-2-45-150$ & 2.89 & 6.66 & 9.59 & 11.0 \\
\hline & $250-2-35-250$ & 1.98 & 4.03 & 5.56 & 5.22 \\
\hline & $300-2-30-150$ & 2.32 & 7.62 & 11.2 & 11.9 \\
\hline & $350-0-30-150$ & 2.96 & 5.73 & 5.76 & 5.70 \\
\hline & $350-1-30-150$ & 5.42 & 10.2 & 12.9 & 13.2 \\
\hline & $350-2-30-200$ & 7.19 & 16.2 & 22.6 & 26.5 \\
\hline & $350-2-30-150$ & 6.02 & 13.6 & 19.8 & 20.3 \\
\hline & $350-2-30-250$ & 3.10 & 6.28 & 8.94 & 10.3 \\
\hline & $\begin{array}{c}350-2-30-150 \\
\text { (Hand } \\
\text { Compaction) }\end{array}$ & 2.28 & 6.03 & 7.80 & 8.43 \\
\hline & $400-2-25-150$ & 6.76 & 13.9 & 19.9 & 21.6 \\
\hline \multirow{4}{*}{$\begin{array}{l}\text { Stone } \\
\text { powder }\end{array}$} & CS 250-2-35 & 2.51 & 5.27 & 7.33 & 8.10 \\
\hline & CS $300-2-30$ & 3.19 & 6.06 & 9.27 & 9.11 \\
\hline & CS $350-2-30$ & 4.42 & 7.84 & 11.7 & 13.7 \\
\hline & CS 400-2-30 & 4.44 & 8.40 & 12.5 & 15.7 \\
\hline
\end{tabular}




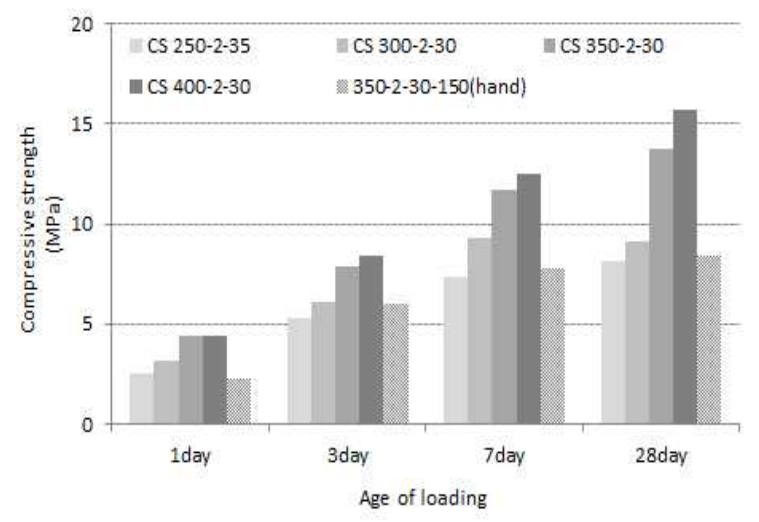

Figure 4. Compressive strength by addition ratio binder

\subsection{Compressive strength by mix proportion of superplasticizer}

As shown in figure 5, when the superplasticizer was added in the ratio of 0,1 , and $2 \%$, strength was developed noticeably at initial age. It was found that the development of strength became slower with the passage of time. In particular, for the specimens with no superplasticizer, there was almost no change in compressive strength after 3 days. For the specimens with $1 \%$ of superplasticizer, strength was developed noticeably with the passage of time, but there was no great change in compressive strength after 7 days. When the specimens that had higher than $350 \mathrm{mix}$ proportion of unit binder, $2 \%$ of plasticizer and w/b ratio of 30 were rammed by the rammer, the compressive strength was measured to be highest above $20 \mathrm{MPa}$. In this case, there was no great change in compressive strength after 7 days. It is believed that strength was prevented from developing by the ramming pattern formed due to not having been rammed after 7 days.

That is, strength at the part with the ramming pattern was measured to be low, and the low density at the part might retard strength development. Through the test results, it was found that when the superplasticizer was added, relatively higher compressive strength was developed, but there was no great change in strength after 7 days.

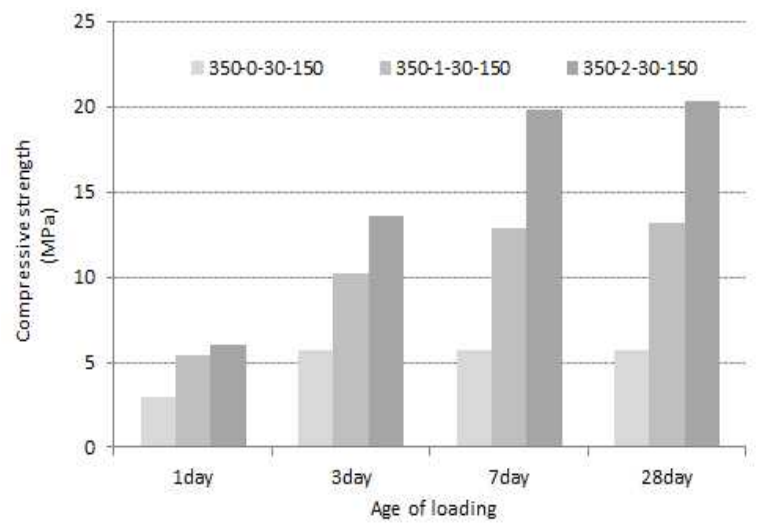

Figure 5. Compressive strength by addition ratio of superplasticizer

\subsection{Compressive strength according to placement height}

As shown in Figure 6, The earth was placed at different heights of $150 \mathrm{~mm}, 200 \mathrm{~mm}$, and $250 \mathrm{~mm}$ using the machine rammer, and rammed. Through the test results, it was found that higher compressive strength was developed at $200 \mathrm{~mm}$ that at $150 \mathrm{~mm}$. However, when set at $250 \mathrm{~mm}$, the compressive strength was found to be greatly decreased. Placement height of $250 \mathrm{~mm}$ is considered appropriate for rammed earth. This result contradicted the general belief that the lower the placement height, the higher the compressive strength. The causes of this result should be clarified through further analysis of ramming pattern, ramming pressure and lateral pressure in future research. In addition, when set at $150 \mathrm{~mm}$, there was no great change in strength after 7 days, while when set at $200 \mathrm{~mm}$, there was a gradual change in strength until 28 days.

\subsection{Compressive strength according to stone powder}

When stone powder was added, overall strength was lower than when sand or aggregate was added. This is believed to be due to grain size. Compressive strength was gradually increased with the passage of time, and showed a different strength property from that of specimens with 


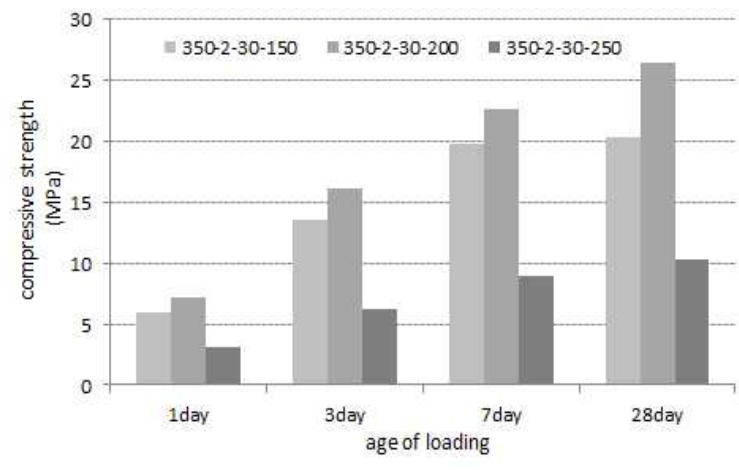

Figure 6 . Compressive strength by earth volume

sand and gravel. As shown in Figure 7, when the mix proportion of binder, superplasticizer, and W/B ratio were equal, the ramming pattern was shown to be more distinct on the specimens mixed with stone powder (Figure 8 b) and d)) than on those with sand and gravel (Figure 8 a) and c)). In terms of ramming pattern, a better effect could be obtained when adding stone powder.

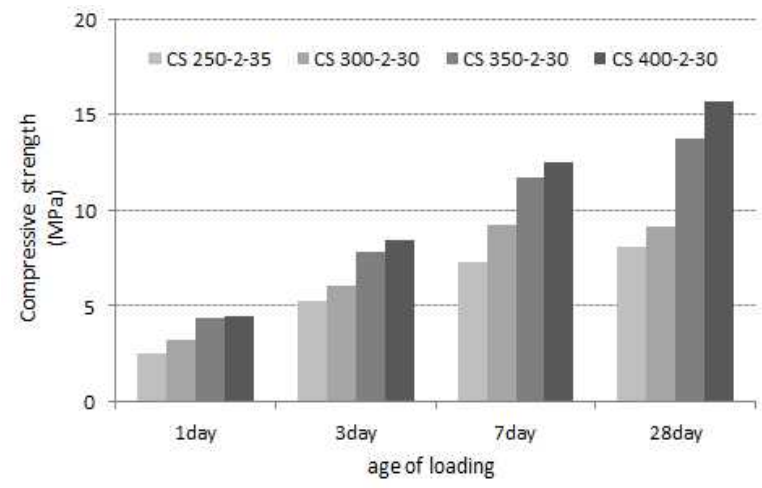

Figure 7. Compressive strength by stone powder

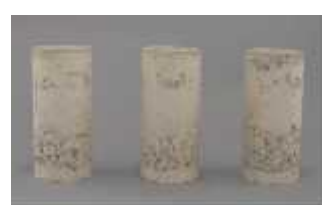

(a) $350-2-30-20$

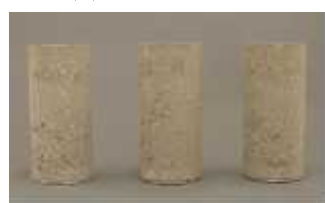

(c) $250-2-35-20$

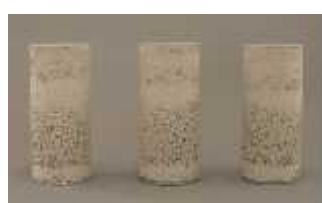

(b) CS-350-2-30

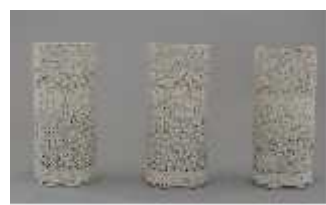

(d) CS-250-2-35
Figure 8. Ramming grain comparison of Test body

\section{Conclusion}

In this study, to improve the weaknesses of conventional rammed earth including high labor cost and durability, compressive strength tests were conducted using Hwangtoh binder. The findings of this research are as follows.

1) In terms of mix proportion of unit binder, the higher the mix proportion of unit binder, the higher the compressive strength overall, as is the case with ordinary cement concrete. At 300 and 400 mix proportion of unit binder, higher strength was developed, and machine ramming was found to have a better effect on strength development than hand ramming.

2) In terms of superplasticizer, compressive strength was greatly developed at initial age in each mix proportion, but it was found that there was no great change in strength after 7 days. It is believed a subsequent analysis of this should be conducted.

3) In terms of placement height, the compressive strength of the specimen rammed after being filled up to $200 \mathrm{~mm}$ was highest compared to that of the specimens rammed after being filled up to $150 \mathrm{~mm}$ or $250 \mathrm{~mm}$. Based on this result, a 200mm placement height was found to be appropriate. Detailed tests should be conducted to clarify the causes of this result.

4) In terms of aggregate, when stone powder was added, the compressive strength was lower than when sand and gravel were added. Notwithstanding this, the strength was gradually developed with the passage of time. However, in terms of ramming pattern and texture, stone powder had a better effect on both of the parts rammed stably or not stably, compared with the sand and gravel. For this reason, if further research is 
conducted on strength, it can be utilized in diverse applications.

Through these experiments, it was revealed that rammed earth mixed with Hwangtoh binder could be applied to middle- and low-story building structures if the strength is improved with the increase of unit binder using superplasticizer within the range of $2 \%$, appropriate $\mathrm{W} / \mathrm{B}$ ratio and ramming pressure. Considering the global trend of environmentally-friendly construction, earth mixed with Hwangtoh binder can have a great effect on reducing $\mathrm{CO} 2$ emission as well as embodied energy. However, more studies need to be conducted on the potential problems, including deterioration in strength caused by ramming pattern and efflorescence.

\section{Acknowledgement}

This study, which forms a part of the project, has been achieved with the support of national $R \& D$ project, which has been hosted by National Research Institute of Cultural Heritage of Cultural Heritage Administration. We express our gratitude to it.

\section{References}

1. Matthew H, David A. Assessing the moisture-contentdependent parameters of stabilised earth materials using the cyclic-response admittance method. Energy and Buildings. 2008 May;40(11):2044-51.

2. Hugo H, Hubert G. Earth Construction A Comprehensive Guide. 1st ed. UK: Intermediate Technology Publications; 1994. p. 6-15.

3. Matthew H, Youcef D. Rammed earth sample production: context, recommendations and consistency. Construction and Building Materials. 2004 May;18(4):281-6.

4. Hwang HZ, Roh TH, Yang JH. A Study on the Proper Mixing Design of Concrete with Hwangto Binder. Journal of the Architectural Institution of Korea (Structure \& Construction). 2007 Jun;23(6):73-80.
5. Hwang HZ, Lee JK, Yang JH. An Experimental Study for basic Properties of Hwangto binder. Journal of the Architectural Institution of Korea (Structure \& Construction). 2008 Jan;24(1):79-86.

6. Hwang HZ. Earth Architecture. 1st ed. Korea: CIR; 2008. p. $114-52$

7. Hwang HZ. Eco-Architecture Technology utilized Traditional Building Materials. Review of Architecture and Building Science. 2008 Mar;52(3):42-5.

8. Jayasinghe C, Kamaladasa N. Compressive strength characteristics of cement stabilized rammed earth walls. Construction and Building Materials. 2007;21(11):1971-6.

9. Lee JK, Kim HC, Lee SW. A Case Study on the Method of High-rise Wall in Rammed Earth Construction. Journal of the Korea Institute of Ecological Architecture and Environment. 2008 Jun;8(3):85-91.

10. Hwang HZ, Kim TH, Yang JH. A study on selection and size of Earth in application of Rammed Earth. Journal of the Korea Institute of Ecological Architecture and Environment. 2009 Apr;9(2):65-71. 